\title{
Variação nos Hábitos Alimentares da Mosca de Estábulos Stomoxys calcitrans $L$
}

\author{
Gonçalves, Neuza Maria Ferraz de Mello* e Veiga, L. A. S. \\ Pontifícia Universidade Católica do Paraná e Instituto de Tecnologia do Paraná PUC/TECPAR - \\ Caixa Postal 16210 - 81.611-970-Curitiba, PR, Brasil.- \\ Universidade Federal do Paraná - Caixa Postal 19046 - 81.531 - 990 Curitiba, PR, Brasil
}

\begin{abstract}
During the course of a study on the behaviour, of Stomoxys calcitrans a research on the feeding habits of this fly was carried out. A total of 2714 flies were caught in three poultry ranches from Araucária, Paraná. The source of the flie's sucked blood has been established by precipitin test. . The results showed that although almost all the flies usually feed mammal blood, some of them gave positive precipitin test for birds blood. Although all flies were caught on poultry ranches, none had feed on chickens but 2,7\% of the total had feed on ducks, $0.7 \%$ on geese and $0.37 \%$ on turkeys.
\end{abstract}

Key words: Stomoxys calcitrans, Stable fly, Precipitin test, Feeding on birds Palavras chaves : Stomoxys calcitrans, Mosca de estábulos, Teste de precipitina, Alimentação em aves

\section{INTRODUÇÃO}

A densa população de $S$. calcitrans que freqüenta os aviários nos meses mais favoráveis (dezembro a maio) transforma-se numa das causas principais responsáveis por sérios prejuízos à avicultura em conseqüência do "stress" produzido por sua picada dolorosa (Anderson \& Tempelis, 1970; Bishopp, 1913).

No Brasil, ainda não foram realizados estudos estatísticos que possam contribuir para a avaliação dos danos causados à avicultura por esta mosca hematófaga, principalmente como conseqüência do estado de "stress" referido. Entretanto, Gonçalves \& Veiga (1994) verificaram a presença de $S$. calcitrans em paredes e tetos de aviários de galinha de postura, causando intranqüilidade à população de aves e, em conseqüência, diminuição de $22 \%$ e $25 \%$ em relação ao peso das aves e à postura de ovos, respectivamente.

A mosca de estábulos S. calcitrans, normalmente não se alimenta com sangue de galinhas. Bishop (1913) foi o primeiro pesquisador a constatar que $S$. calcitrans ocasionalmente em galinhas, em campo aberto. SÉGUY (1935) e GOLDING (1946) relataram o ataque destas moscas em galinhas, principalmente nas regiões desprovidas de penas, como é o caso das cristas. BOS (1934) verificou que as moscas criadas em laboratórios podiam alimentar-se em galinhas quando não havia outra opção. Gonçalves \& Veiga (1994, 1995), verificaram a influência da temperatura na ocorrência de $S$. calcitrans e identificaram o comportamento alimentar de 2.174 exemplares desta mosca em relação a mamíferos existentes nas redondezas dos aviários de galinha de postura. $\mathrm{Na}$ ocasião, confirmaram as experiências dos autores acima, ao colocarem exemplares desse inseto em contato direto com a pele das galinhas.

O presente trabalho teve por objetivo contribuir para o estudo do comportamento alimentar de $S$. calcitrans, principalmente pela inclusão do sangue de outras aves existentes nas redondezas dos aviários estudados.

\footnotetext{
* Autor para correspondência
} 


\section{MATERIAL E MÉTODOS}

A captura dos insetos foi realizada no município de Araucária, Paraná, em três aviários de criação de galinhas de postura, distantes $5 \mathrm{~km}$ entre si e identificados como aviários I, II e III. Após a captura, os insetos foram acondicionados em sacos plásticos etiquetados e anestesiados em atmosfera de clorofórmio. O sangue sugado foi extraído por compressão do abdômen das moscas entre papéis de filtro Whatman N.$^{\circ} 4$, em seguida acondicionados em frascos de vidro estéreis e estocados a $-20^{\circ} \mathrm{C}$, para serem utilizados como antígeno na reação de precipitina.

Para a preparação de antígenos utilizados posteriormente para obtenção de anticorpos em coelhos, foram usadas diversas aves domésticas: galinha (Gallus gallus domesticus) cedida pelos proprietários do aviário Santa Maria, pato (Cairina moschata) e ganso (Anser anser) pelo aviário Santa Vera e peru (Meleagris gallopavo) procedente do aviário Quatro Barras, todos do Município de Araucária. Desses animais, o sangue foi colhido por punção cardíaca, incubado a $37^{\circ} \mathrm{C}$ por 30 minutos, e o soro separado por decantação e mantido a $4^{\circ} \mathrm{C}$. Após 12 horas, houve nova retração do coágulo e o soro obtido foi adicionado ao primeiro. $\mathrm{O}$ soro resultante foi centrifugado em centrífuga refrigerada a $1200 \mathrm{rpm}$ por 20 minutos para separação de lipídios (Mcfarlane, 1942). Aos soros, distribuídos em alíquotas de $6 \mathrm{ml} \mathrm{em}$ frascos de vidro, foi adicionado $0,05 \mathrm{ml}$ de solução de azida de sódio a $0,1 \%$ e então estocados a $-20^{\circ} \mathrm{C}$.

Um lote de 12 coelhos, originários da Granja Maria Luiza, do Instituto de Tecnologia do Paraná, foi acondicionado em gaiolas individuais de arame, medindo 60x50x43 cm e alimentados diariamente com ração Purina ${ }^{\circledR}$ e água. O sangue desses animais (3 a $5 \mathrm{ml}$ ), colhido por punção, foi incubado a $37^{\circ} \mathrm{C}$ por 30 minutos e o soro foi obtido por centrifugação a $1200 \mathrm{rpm}$ por 15 minutos à temperatura ambiente.

Os soros dos coelhos e das aves utilizados nos experimentos foram analisados pela técnica do "ring test" para verificar a possibilidade da existência de reação cruzada. O soro dos coelhos foi adicionado lentamente, com auxílio de pipeta Pasteur, no fundo de um tubo de Durhan. Como antígeno, o soro das aves nas proporções de 50 a $100 \mu \mathrm{g} / \mathrm{ml}$ de proteínas em diluições de $1: 2$ a 1:16 em $\mathrm{NaCl}$ a $0,15 \mathrm{M}$, foi adicionado pelas paredes dos tubos. Os resultados foram verificados imediatamente após a adição do antígeno, a 15 minutos e a 2 horas pela presença de um anel entre as fases (Pelczar et al , 1981).

A concentração de proteínas foi determinada nas amostras de antisoros e de antígenos pelo método de Lowry et al (1951).

Anticorpos foram obtidos de 12 coelhos injetando, na região dos nódulos linfáticos, emulsões preparadas com soro de aves e adjuvante de Freund. Cada coelho recebeu 4 inoculações de $1 \mathrm{ml}$, com 10 dias de intervalo. A primeira inoculação foi preparada com $70 \mu \mathrm{g} / \mathrm{ml}$ de proteínas de soro de aves e $50 \mu \mathrm{g} / \mathrm{ml}$ de adjuvante completo de Freund. As três inoculações seguintes foram preparadas com 60 $\mu \mathrm{g} / \mathrm{ml}$ de proteína de soro de aves e $40 \mu \mathrm{g} / \mathrm{ml}$ de adjuvante de Freund. O título de anticorpos foi determinado semanalmente após a segunda inoculação, pela técnica da dupla difusão de OUCHTERLONY (1958). Para tanto, o sangue dos coelhos foi colhido (4 a $6 \mathrm{ml}$ ) pela veia marginal da orelha.

Para a execução da reação antígeno-anticorpo, pelo teste da precipitina, o papel de filtro Whatman $n^{\circ} 4$, contendo o sangue ingerido pelas moscas, foi recortado em pequenos pedaços e colocado em tubos de ensaio contendo $1 \mathrm{ml}$ de soro fisiológico, até completa eluição. No material sem nenhum tratamento prévio a concentração de proteína foi determinada pelo método de LOWRY et al. (1951).

As experiências de imunodifusão foram realizadas segundo o método de Ouchterlony \& Nilsson (1978) em lâminas de gel a 1,5\% (Difco Special Agar Noble). As bandas de precipitação forma coradas com Comassie brilliant blue G250 (Blakesley \& Boezi, 1977). 


\section{RESULTADOS}

Em todos os ensaios efetuados para afastar possíveis interferências de reações cruzadas, não houve evidências de reações de precipitações pelo "Ring test" (Pelczar et al., 1981).

A imunização dos coelhos, realizada na região dos nódulos linfáticos, produziu títulos máximos de anticorpos após a terceira inoculação (Tabela I). Foi observado que a estocagem de soros precipitantes a $-20^{\circ} \mathrm{C}$, por 14 meses, não alterou significativamente os títulos homólogos dos mesmos.

A tendência alimentar da $S$. calcitrans pelo sangue de diferentes aves, determinada pelo método de imunodifusão, está mostrada nos resultados apresentados na Tabela II. Verificouse, também, que há elevada presença dessas moscas nos aviários, provavelmente em razão do processo de oviposição que é realizado sobre as fezes secas acumuladas debaixo das gaiolas das galinhas. Todos os 2174 exemplares de $S$. calcitrans capturados, apresentaram reaçãonegativa para os imunosoros de galinha. secas acumuladas debaixo das gaiolas das galinhas. Todos os 2174 exemplares de $S$. calcitrans capturados, apresentaram reaçãonegativa para os imunosoros de galinha.
Tabela I : Títulos de soros precipitantes obtidos com antígenos homólogos .determinados pela técnica de Ouchterlony (1958)

Soro

Título $(\mu \mathrm{g} / \mathrm{ml})$

Anti-pato

10.300

Anti-ganso

10.500

Anti-peru

Anti-galinha

22.700

Foram realizadas 1513 reações para as moscas capturadas no aviário I, 718 no Aviário II e 483 no Aviário III.

\section{DISCUSSÃO}

O objetivo da presente pesquisa foi o de relatar as ocorrências incomuns de alimentação de $S$. calcitrans com sangue de aves. Para tanto, foram capturados nos aviários estudados 2174 exemplares de $S$. calcitrans, $60,5 \%$ de fêmeas e $39,5 \%$ de machos (Gonçalves \& Veiga, 1995), resultado que coincidiu com os encontrados por Anderson \& Tempelis, 1970. A Tabela II mostra resultados expressos em percentagem de sangue colhido do abdômen de S. calcitrans, verificados pelo teste de precipitina, apresentando positividade nas

Tabela II : Tendência alimentar de S. calcitrans capturada em aviários de postura, determinada pelo teste de precipitina

\begin{tabular}{lcccccc}
\hline $\begin{array}{c}\text { Fonte de } \\
\text { Alimentação } \\
\text { (sangue) }\end{array}$ & \multicolumn{2}{c}{ Aviário I } & \multicolumn{2}{c}{ Aviário II } & \multicolumn{2}{c}{ Aviário III } \\
\hline & $\begin{array}{c}\text { Reações } \\
\text { Positivas }\end{array}$ & Moscas \% & $\begin{array}{c}\text { Reações } \\
\text { Positivas }\end{array}$ & Moscas \% & $\begin{array}{c}\text { Reações } \\
\text { Positivas }\end{array}$ & Moscas \% \\
\cline { 2 - 8 } Pato & 42 & 2,77 & 14 & 1,95 & 16 & 3,32 \\
& 13 & 0,86 & 3 & & & \\
Ganso & 9 & 0,60 & 2 & 0,42 & 4 & 0,83 \\
Peru & 0 & 0,00 & 0 & 0,27 & 1 & 0,20 \\
Galinha & & & & 0,00 & 0 & 0,00 \\
\hline
\end{tabular}

amostras de sangue em diversas aves domésticas, com exceção do sangue de galinha, para o qual todos ostestes foram negativos. Portanto, dos 1513 insetos capturados no aviário I, $42(2,77 \%)$ alimentaram-se em patos, $13(0,86 \%)$ em gansos, e $9(0,60 \%)$ em perus; dos 718 insetos capturados no aviário II, $14(1,95 \%)$ alimentaram-se em patos, $3(0,42 \%)$ 
em gansos e $2(0,30 \%)$ em perus; dos 483 insetos capturados no aviário III, $16(3,34 \%)$ alimentaram-se em patos, $4(0,83 \%)$ em gansos e somente o sangue de uma mosca apresentou reação positiva para sangue de peru.

Nenhum dos 2174 insetos capturados nos três aviários apresentou reação positiva para sangue de galinha, confirmando os resultados encontrados por Anderson E Tempelis (1970). A alimentação em galinha só ocorreu quando $S$. calcitrans não encontrava outra opção, como nos casos descritos por Bos (1934), Mitzmain (1913) E Gonçalves \& Veiga (1994). Mesmo os casos relatados aqui, de alimentação de $S$. calcitrans em sangue de aves, podem ser considerados como casos raros, o que não acontece com mosquitos, que usualmente se alimentam também de sangue de mamíferos (Tempelis, et al., 1970; Tempelis et al., 1967; Zòltowski et al., 1978 ).

A adição de azida de sódio ao soros como agente bacteriostático, não alterou suas propriedades quando estocados a $-20^{\circ} \mathrm{C}$, nem causou turvação, como afirmou Weitz (1960).

A mosca S. calcitrans apresentou comportamento alimentar eclético, dando preferência ao sangue de mamíferos (ANDERSON \& Tempelis, 1970; Gonçalves \& Veiga, 1994), utilizando os aviários como um local de criação, uma vez que as fezes secas acumuladas sob as gaiolas das galinhas revelaram ser material adequado e preferido para a oviposição. Eventualmente, os insetos adultos usam alimentar-se em sangue de algumas aves, mas não em sangue de galinha, segundo os dados do presente trabalho.

A captura de 2.174 exemplares de $S$. calcitrans proporcionou amostras suficientes para o estudo da influência da temperatura na ocorrência desta mosca (Gonçalves \& Veiga, 1994) e também para a pesquisa de identificação da origem do sangue sugado, verificando a preferência em sangue de mamífero (Gonçalves \& Veiga, 1995) . Utilizando as mesmas amostras das duas pesquisas anteriores (Gonçalves \& Veiga, 1994; Gonçalves \& Veiga, 1995), foi possível, então, estudar a variação nos hábitos alimentares da $S$. calcitrans, em relação ao sangue de algumas aves existentes nas redondezas, em até $5 \mathrm{Km}$ de distancia dos aviários pesquisados.

\section{REFERÊNCIAS}

Anderson, J.R. \& Tempelis, C.H. Precipitin test identification of blood meals of Stomxs calcitrans $L$. caught on California poultry ranches and observation of digesion rates of bovine

and citrated human blood. J.Med.Entomol. v.7, p.233-239, 1970.

Bishopp, F.C. The stable fly Stomoxys calcitrans $(\underline{L}), \quad$ an important livestock pest

J.Econ.Entomol.v.6,p.112-126, 1913.

Blakesley, R.W. \& Boezi, J.A. A new staining technique for proteins in polyacrylamide gel using coomassie brilliant blue G 250 . Anal. Biochem. v.82 p. 580-582, 1977.

Bos, A.Beitrag zur kenntnis der geflfügelpodremibetragung durch Nücken und anche Arthropoden, Z.Infekt.Kr.Haust. v.46, p. 195-259, 1934.

Golding, F.D. A new method of trapping flies; Bull. Entomol.Res. v. 37 p.143-154, 1946.

Golçalves, N.M.F.M. \& Veiga, L. Identificação da origem do sangue sugado por Stomoxys calcitrans, (L.) mosca dos estábulos capturadas em aviários do Paraná, pelo teste da precipitina. Arq. Biol. Tecnol. v.38, n.4, p.1217-1224,1995.

Gonçalves, N.M.F.M \& Veiga, L.A. Inflluência da temperatura na ocorrência de Stomoxys calcitrans (L.) em aviários de aves de postura (Gallus gallus). Arq.Biol.Tecnol., v. 37 p. 853-864, 1994 .

Lowry, O.H., Rosenbrough, N.V., Farr, R.V. \& Randall, R.J.. Protein mesurement with the Folin phenol reagent. J. Biol. Chem., v. 193, p. 265-271, 1951.

McFarlane., A S.. Behaviour of lipoids in human serum. Nature, v. 149, n. 3781 p.439, 1942.

Mitzmain, M.B. The bionomics of Stomoxys calcitrans (L.): a preliminary account. Philip.J. Sci .v. 8 n.B, p. 29-48, 1913.

Ouchterlony, O. \& Nilsson, I.A.. Immunodifusion and Immunoelectrophoresis. In: Weis, D. Ed. Handbook of Experimental Immunology Oxford, Blackwell, 1978. p. 1911, 1944. 
Ouchterlony, O. Diffusion in gel methods for immunological analysis. In: Prog. Allergy v. 5, p. 1-78 p. Basel/ New York, S. Karjer, 1958.

Pelczar, M., Reid, R \& Cham, E.C.S. Microbiologia, New York, McGrew-Hill, v.2 p. 1072, 1981.

Sèguy, E..Etudes sur les stomoxydines et particulierèment des mouches charbonneuses du genre Stomoxydines. In: Encyclopedie Entomologique, Paris, Serv. B., v. 2, n. 8, p. 24-335, 1935.

Tempelis, C.H.. Use of the pheasant (Phasianus torquatus) to produce a specific antichicken serum. Proc. Soc. Exper. Biol. Med. v. 110, p. 393-394, 1962 .

Tempelis, C.H. \& Reeves, W.C. The production of a specific antiserum to bird serum. Am J.Trop.Med.Hyg. v. 11 n. 2, p. 294-297, 1962.
Tempelis, C.H., Francy, D.B., Hayes, R.O. \& Lofy, M.F. Variations in feeding patterns of seven culicine mosquitoes on vertebrate hosts in Wel and Larimer counties, Colorado. Am. J. Trop.Med. Hyg. v. 16, n.1, p.111-119, 1967.

Tempelis, C.H., Hayes, R.O., Hess, A.D. \& Reeves, W.C. Blood-feeding habits of four species of mosquitoes found in Hawai. Am. J. Trop. Med. Hyg. v.19 n. 2, 335-341, 1970.

Weitz, B. Feeding habits of blood-sucking arthropods Exp.Parasitol v..9, p. 63- 82, 1960.

Zòltowski,Z., Stejgwillo-Laudanska, B. and Kazmierczukj. Studies on host ranges and food preferences of forest mosquitoes of the genus Aedes, Meigen 1818 (Diptera, Culicidae). Acta. Parasitol. Pol, v.26, n. 31, p. 257-265, 1978. 